\title{
A study on transition process to MEB by limiting boiling space
}

\author{
Kendai KAWAKAMI*, Shosuke SAKAMOTO*, Hirofumi TANIGAWA** and Takaharu TSURUTA** \\ *Graduate School of Mechanical Engineering, Kyushu Institute of Technology \\ 1-1 Sensui-cho, Tobata-ku, Kitakyushu-shi, Fukuoka, 804-8550, Japan \\ **Department of Mechanical Engineering, Kyushu Institute of Technology \\ 1-1 Sensui-cho, Tobata-ku, Kitakyushu-shi, Fukuoka, 804-8550, Japan \\ E-mail: tsuruta.takaharu393@mail.kyutech.jp
}

Received: 22 May 2020; Revised: 11 August 2020; Accepted: 17 September 2020

\begin{abstract}
The study of microbubble emission boiling (MEB) is gaining popularity because it violently emits several microbubbles during subcooled pool boiling, for which the heat flux is greater than the critical heat flux (CHF). Although the occurrence of MEB and the heat transfer mechanisms have been analyzed, several aspects of this phenomenon are unknown. In this study, the behavior of coalesced bubbles that form above the primary bubbles on a horizontal heat transfer surface are focused. Experimental observations of boiling behavior, including the transition process from nucleate boiling to MEB, were conducted under the subcooling condition of $40^{\circ} \mathrm{C}$. The transition from nucleate boiling to MEB was found to occur below the CHF when the boiling space was limited to a height lower than that of the coalescent bubbles. Furthermore, the following two types of transitions were observed, depending on the heat flux considering the restriction of the boiling space: from nucleate boiling to MEB, or from nucleate boiling to film boiling. The restriction of boiling space reduces the condensation rate of coalesced bubbles and increases partial dryout. The surface dryout has two possibilities: promoting the transition to film boiling and reducing the vapor supply to the coalesced bubbles. The latter results in a shrinkage of the coalesced bubbles which induces the direct contact of subcooled liquid to the heat transfer surface. The high heat transfer rate in MEB may be attributed to the direct contact between the solid and liquid, along with microlayer evaporation.
\end{abstract}

Keywords : Boiling heat transfer, Subcooled pool boiling, Transition boiling, Microbubble emission boiling, Coalesced bubble, Evaporation and condensation, Dryout, MEB transition, Direct contact heat transfer

\section{Introduction}

The study of microbubble emission boiling (MEB) in which the heat flux exceeds the critical heat flux (CHF) while emitting several microbubbles during subcooled boiling is gaining attention. MEB has a unique boiling behavior that was identified by Inada et al. (1981). In addition to the elucidation of the phenomenon, the application to cooling technology such as electronic devices is anticipated (Suzuki, 2017; Tange, 2017; Ueno, et al., 2017). Several studies have considered the instability of the liquid-vapor interface of coalesced bubbles, with an emphasis on the condensation disappearance process of coalesced bubbles in the subcooled region, as the main factor for inducing a high heat flux (Ueno, et al., 2015; Tang, et al., 2017; Tang, et al., 2018; Tang, et al., 2019a). To elucidate the effect of a subcooled liquid supply to the heat transfer surface, velocity field measurements near the heat transfer surface have been performed via a particle image velocimetry (PIV) (Ito, et al., 2017). It is interesting to note that the disappearance of coalesced bubbles which creates a rapid flow of subcooled water to the heat transfer surface initiates the transition to MEB (Ando, et al., 2016). The microbubbles observed in the subcooled pool are easily assumed to be simple dissolved gas being released, instead of vapor bubbles (Zeigamik, et al., 2012). When the liquid layer on the heat transfer surface evaporates, the non-condensable gas dissolved in the liquid phase is entrained in the bubbles along with the vapor. During the condensation disappearance of the bubbles, non-condensable gas is released from the interface as microbubbles and remains in the subcooled water. 
This characteristic behavior of the microbubbles is significant, however, the study of the heat transfer phenomenon on the heat transfer surface remains insufficient. There are limited explanations regarding high-heat flux despite the existence of the superheated region beyond CHF.

Although MEB occurs on a flat heat transfer surface, it cannot occur on a heating wire (Kishihara, et al., 2016; Nakamura, et al., 2018). The effect of the heat capacity of heat transfer surface, i.e. the thermal interaction of subcooled water and the heat transfer surface, is significant for MEB. An experiment using a copper horizontal surface with a diameter of $7 \mathrm{~mm}$ was recently conducted. By measuring the boiling curve and closely observing the behavior of the primary bubbles that form on the heat transfer surface using a high-speed camera, the occurrence mechanism of MEB was investigated (Nakamura, et al., 2018). Specifically, the primary bubbles on the heat transfer surface were examined. We assumed that the heat transfer near the heat transfer surface was close to saturated boiling, and the microlayer model developed for saturated pool boiling was simply expanded (Zhao, et. al., 2002) to subcooled boiling to compare the predicted and experimental results. The important point was that in the high heat flux region, latent heat transport via evaporation of the microlayer that forms under the primary bubbles and sensible heat transport via direct contact between the subcooled water and the dryout surface created by the evaporation of liquid layer plays an important role. The importance of direct contact heat transfer has also been suggested by Kumagai et al. (2001).

In this study, the growth or shrinkage of the coalesced bubbles is considered to depend on the rate balance between the evaporation of the liquid layer on the heat transfer surface and the condensation at the upper surface of the coalesced bubbles. Therefore, an experiment was conducted in which an imbalance in the evaporation and condensation was caused by limiting the space above the heat transfer surface to promote the occurrence of the direct contact of water to the dryout surface. A solid baffle rod was placed above the heat transfer surface to artificially control the condensation by subcooled water. The results indicated that two types of transitions occur prior to CHF: from nucleate boiling to MEB, and from nucleate boiling to film boiling, depending on the spatial limitation. The transition mechanism to MEB is investigated in this study by comparing the changes in these two boiling behaviors.

\section{Experimental apparatus and methods}

\subsection{Experimental apparatus}

Figure 1 presents a schematic diagram of the experimental apparatus, which consisted of a copper heat transfer block heated by an electric heater and a water tank. The boiling heat transfer surface was a horizontal upward surface. The water tank was $250 \times 250 \times 250 \mathrm{~mm}$ in size composed of polycarbonate. A glass observation window and a separate window for lighting were provided at the height of the heat transfer surface. A copper cooling coil that was cooled by water circulation and two $1 \mathrm{~kW}$ auxiliary heaters were positioned in the tank. The temperature was regulated to maintain a constant target subcooled temperature. The water temperature was monitored by a K-type thermocouple placed $10 \mathrm{~mm}$ above the heat transfer surface to ensure the temperature remained at $60 \pm 1{ }^{\circ} \mathrm{C}$.

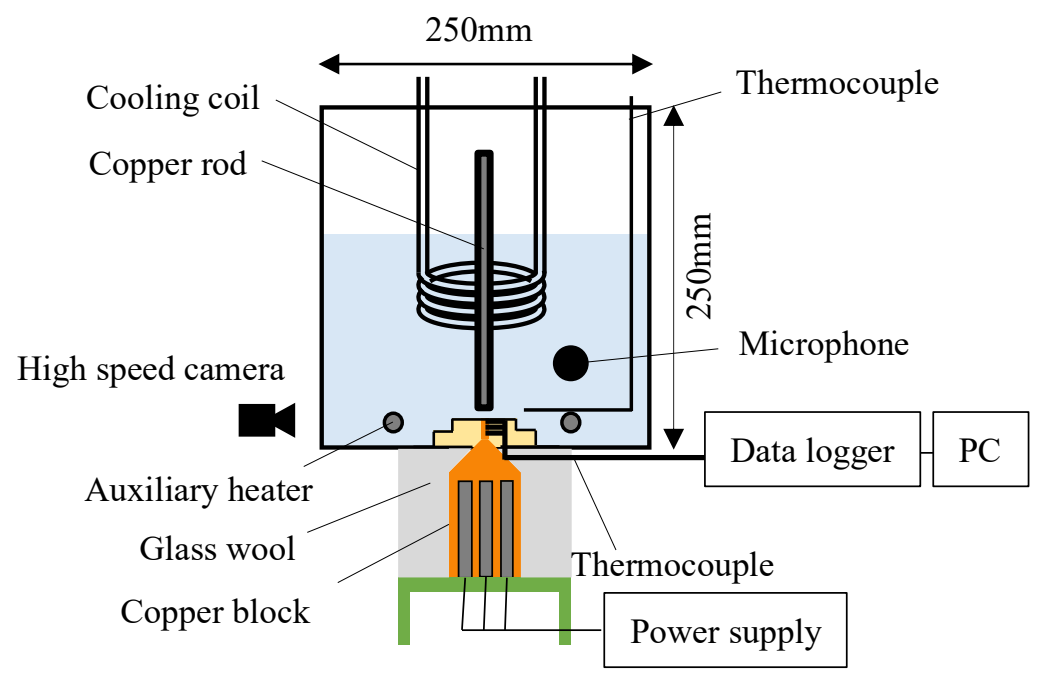

Fig.1 Experimental apparatus 

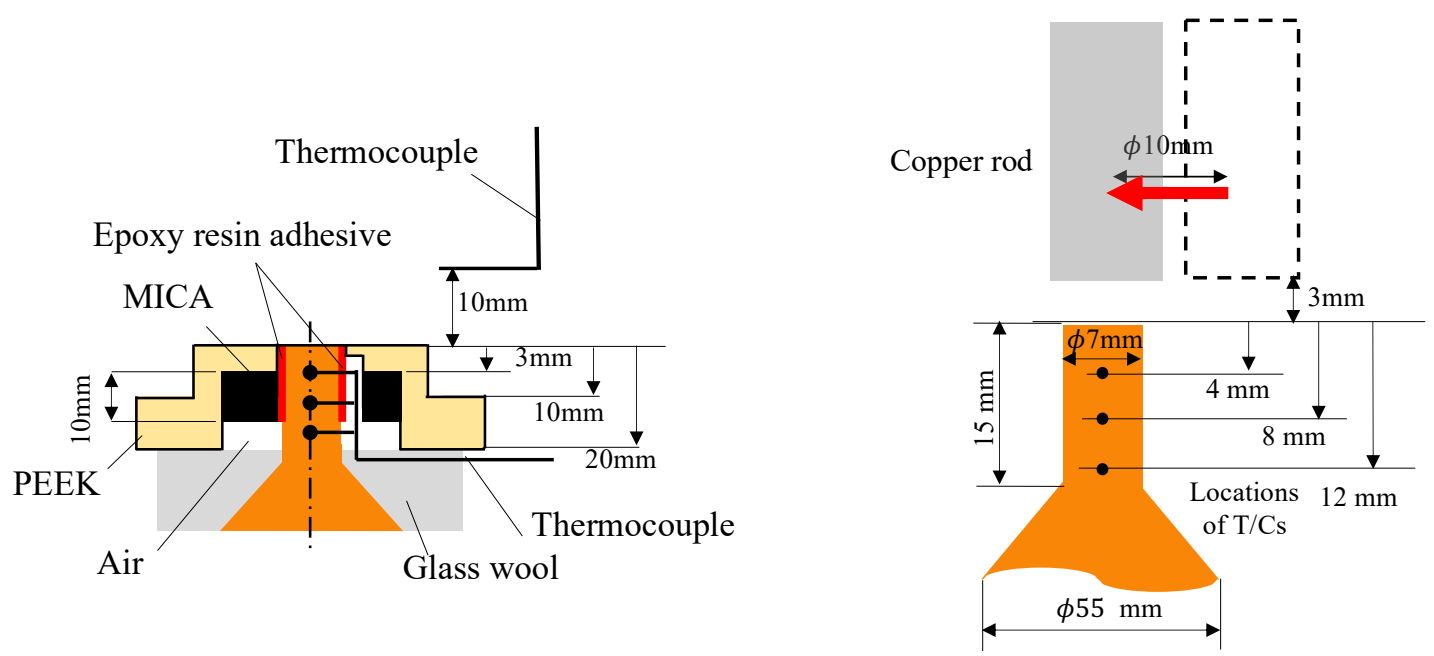

Fig.2 Details of heat transfer section and method of boiling space confinement.

The heat transfer block was prepared from a copper cylinder with a diameter of $55 \mathrm{~mm}$ and a length of $139 \mathrm{~mm}$. The top part was used as a cylindrical test section with a diameter of $7 \mathrm{~mm}$ and a length of $15 \mathrm{~mm}$, as shown in Fig. 2. Five cartridge heaters $(450 \mathrm{~W})$ were inserted in the bottom part, and heating was regulated in a stable manner via a parallel connection to a power device of $1600 \mathrm{~W}$. This heat transfer block was covered using a $60 \mathrm{~mm}$ thick (in the radial direction) glass wool insulation. Figure 2 presents the test section indicating the thermal and water insulation methods. MICA and PEEK were used as solid insulating materials for the high temperature, and an epoxy resin adhesive was used for water sealing. The size of the heat transfer surface was smaller than half of the wavelength for the Rayleigh-Taylor instability (ca. $16 \mathrm{~mm}$ ). Its surface was polished with \#1000 sandpaper for each experiment and washed with acetone. As shown in Fig. 2, type K sheathed thermocouples were inserted at $4 \mathrm{~mm}, 8 \mathrm{~mm}$, and $12 \mathrm{~mm}$ from the heat transfer surface, and the temperature distribution of the test section was recorded using a datalogger. The heat flux and the surface temperature were evaluated using the method of least squares assuming one-dimensional heat conduction. In addition, a high-speed camera (Photron FASTCAM MC2.1) was installed outside the water tank to observe the boiling behavior, and a hydrophone was placed in the water to capture the sound of boiling.

\subsection{Experimental methods}

Commercially available distilled water was used as the experimental fluid. After pouring $4 \mathrm{~L}$ of distilled water in the water tank, the water was heated up to approximately $100{ }^{\circ} \mathrm{C}$ using an auxiliary heater in the water tank for degassing; the boiled state was maintained for approximately one hour while using the coil cooler as the condenser. Subsequently, the coil cooler was returned to the water and the temperature was lowered to the target subcooled temperature. The heating of the copper block was then initiated. After confirming that the heat transfer surface temperature reached the specified constant temperature, images of the bubble behavior were acquired using a high-speed camera with a speed of 4,000-10,000 fps, and image size of 512 pixels $\times 512$ pixels. During the image acquisition process for boiling behavior, the speed was primarily 4,000 fps. However, when observing bubbling behavior, such as the bubble generation cycles and the diameter of the bubbles on the heat transfer surface, an acquisition speed of 10,000 fps was used. After the images were acquired, the output of the power device was changed, and imaging was repeated after the heat transfer surface temperature became stable.

By installing a copper cylinder edge on the upper part of the boiling surface, the space was limited for the coalesced bubbles on the heating surface, as shown in Fig. 2. Various materials were compared for the cylinder including copper, acrylic, and wood; no difference was determined between these materials. Thus, in this study, only copper bars of $10 \mathrm{~mm}$ in diameter were used, and the height limit of the space was set to $3 \mathrm{~mm}$ without any changes. Near the CHF, where there was no spatial limit, the height of the coalesced bubbles was 5-6 mm, which indicates that the height was restricted to approximately half. 


\section{Result and discussion}

\subsection{Boiling curve in open space}

First, the boiling curve in a regular open space was examined without any spatial restriction, and vapor bubble images were obtained using the high-speed camera shown in Fig. 3. The current heat transfer data in the boiling curve indicated a slightly higher CHF and MEB heat flux compared to previous references (Ando, et al., 2016; Suzuki and Inagaki, 2005). The surface superheat decreased with an increasing heat flux during MEB. Because similar behavior was recently reported, the heat transfer performance in MEB should be examined precisely by considering the effect of surface wettability (Unno, et al., 2017). Considering the bubble behavior in the region of nucleate boiling, several primary bubbles of a submillimeter size were observed on the heat transfer surface, and coalesced bubbles (secondary bubbles) were observed across the heat transfer surface. The subcooled water contained many small bubbles which rose as a plume from the center of the heat transfer surface. Given that these bubbles were in subcooled water, it is apparent that they were not vapor bubbles, but rather contained non-condensable gas. Similar to a report by Zeigarnik et al. (2012), the dissolved non-condensing gas was entrained in bubbles during the formation of the primary bubbles, and noncondensable gas was left behind while the vapor condensed in the subcooled water. They also observed that despite vacuum degassing, these bubbles do generate and become microbubbles during condensation of the bubbles. In this experiment, the microbubbles separated from relatively large coalesced bubbles at the time of condensation. The ascending flow from the center of the heat transfer surface induced a descending flow to the area near the heat transfer surface. Temperature field measurements confirmed that the area near the heat transfer surface was maintained at the subcooled temperature.
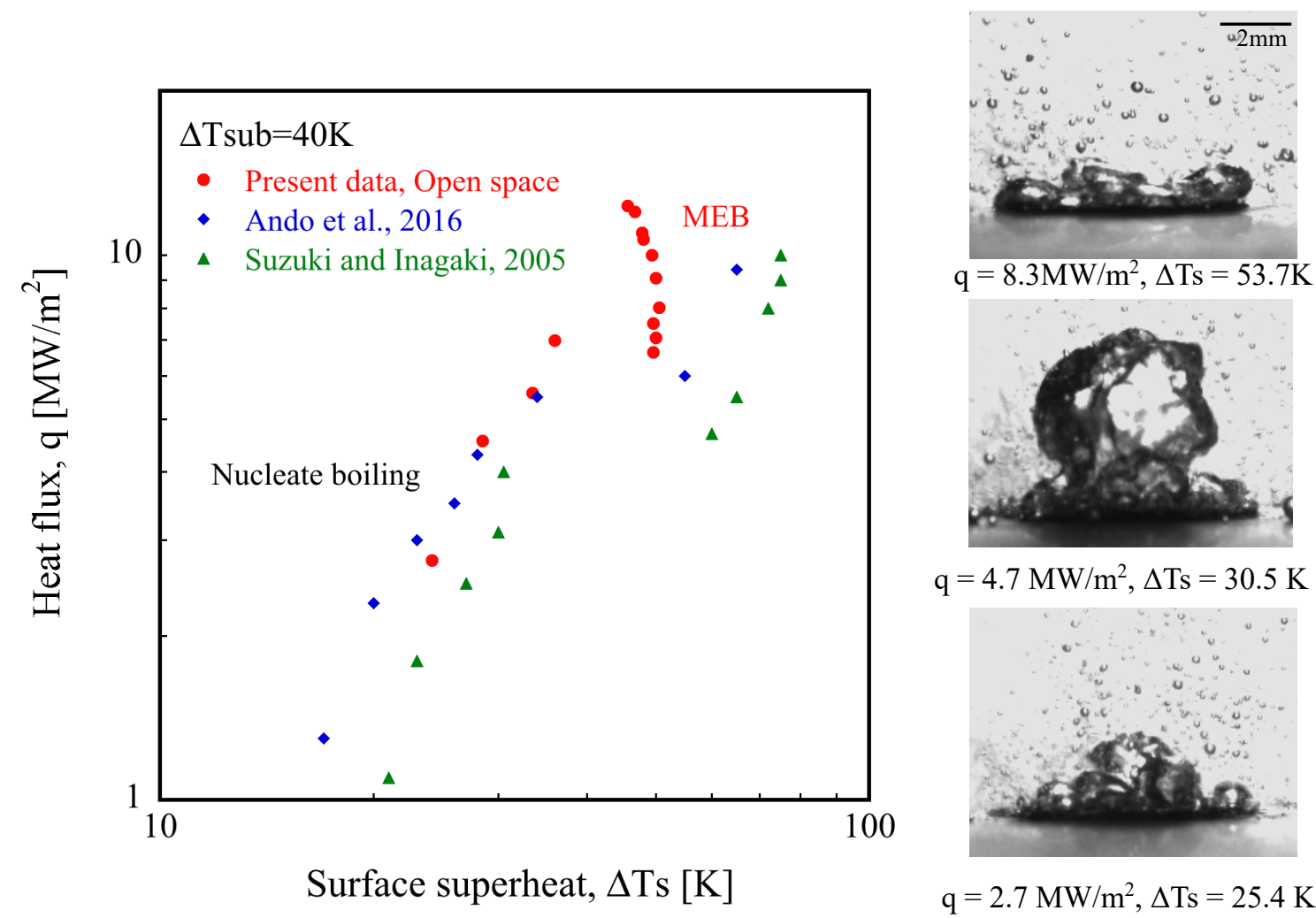

$\mathrm{q}=2.7 \mathrm{MW} / \mathrm{m}^{2}, \Delta \mathrm{Ts}=25.4 \mathrm{~K}$

Fig. 3 Boiling curve on horizontal surface for open space and bubble behavior.

When the heat flux was increased, a massive coalesced bubble formed at the center of the heat transfer surface. During its condensation, large bubbles of non-condensable gas were separately formed, becoming mixed with microbubbles. The primary bubbles were also observed on the heat transfer surface, and coalescence of primary bubbles in the lateral direction was promoted. The heat transfer surface was approximately half the size of the wavelength for the Rayleigh-Taylor instability. Thus, one coalesced bubble formed at the center of the heat transfer surface. A large coalesced bubble existed stably because the entry of low-temperature liquid to the center of the heat transfer surface was 
inhibited. In the MEB region, coalesced bubbles were observed in multiple locations on the heat transfer surface, and rapid condensation and growth was repeated, which reduced the height of the coalesced bubbles. This demonstrates that the subcooled water approached the heat transfer surface.

In this experiment, bubbles that formed without condensing despite being in the subcooled water were collected, and their volume was measured using a graduated cylinder by installing an upside-down funnel on top of the boiling heat transfer surface. The time taken to reach the specified volume was measured, and the production per unit time was evaluated. Figure 4 presents the volume rate of non-condensable gas captured for each superheating case, along with the mean maximum height of the coalesced bubble. Regarding nucleate boiling, the volume rate of non-condensable gas increased as superheating increased. However, it decreased for MEB, sufficiently corresponding to the change in the height of the coalesced bubbles. Kumagai and Kubo (1999) also reported an identical observation regarding bubble height. Considering non-condensable gas is emitted from coalesced bubbles, such gas was entrained in the bubbles with vapor when the primary bubbles, the source of coalesced bubbles, were generated. The generation of non-condensable gas increased with an increase in the latent heat transport. However, in the MEB region, the height of the coalesced bubbles and the recovery of non-condensable gas decreased under approximately the same amount of superheating, as shown in Fig. 4. This indicates that for MEB, the generation of primary bubbles on the heat transfer surface was reduced. Thus, the generation of vapor and non-condensable gas was also reduced. Therefore, as experimentally presented by Ono and Sakashita (2009), the liquid layer on the surface dries locally due to evaporation, increasing the dryout area and reducing the latent heat transfer in the MEB region beyond CHF. Consequently, this causes a reduction in the supply of vapor and non-condensable gas to coalesced bubbles. Given that the amount of condensation due to subcooled water reduced the height of the coalesced bubbles, the likelihood of solid-liquid direct contact (high-temperature heat transfer surface and subcooled water) increased, thereby increasing the contribution of sensible heat transport.

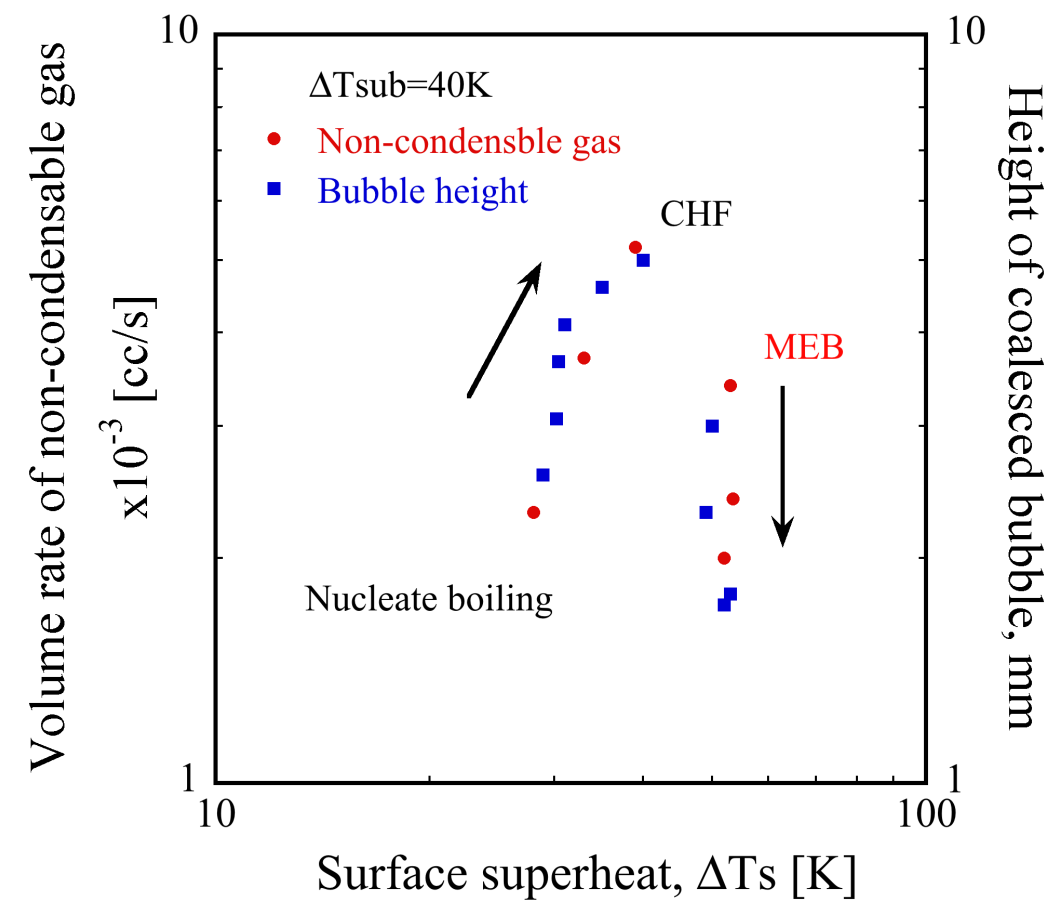

Fig. 4 Volume rate of collected non-condensable gas and mean-maximum-height of coalesced bubble.

\subsection{Changes in the boiling curve and boiling behavior due to spatial limitation}

It is evident that the balance between evaporation on the heat transfer surface and condensation on the top surface of coalesced bubbles determines the growth and shrinkage of coalesced bubbles. Considering the aforementioned behavior of coalesced bubbles and non-condensable gas, this point is extremely important for transition to MEB. Thus, to artificially cause an imbalance between evaporation and condensation, we conducted an experiment in which the space 
above the heat transfer surface was restricted. The result is shown as the boiling curve in Fig. 5. The boiling curve for an open space without any spatial restrictions is also shown for comparison; however, in this case, it transitioned to MEB in the region that exceeds CHF, where a jump in the superheat and a slight decrease in heat flux could be confirmed. When the boiling space was restricted, there were generally two transition patterns (Fig. 5(a) and (b)). Although the heat flux was lower than CHF, with heat flux $q=4 \mathrm{MW} / \mathrm{m}^{2}$ and superheat $\Delta \mathrm{Ts}=25 \mathrm{~K}$ as the boundary, if space was restricted when the heat flux and superheating exceeded these values, it transitioned to MEB (Fig. 5(a)). Spatial restriction at a heat flux below $4 \mathrm{MW} / \mathrm{m}^{2}$ led to a transition to film boiling (Fig. 5(b)). In this experiment, the boiling sound in water was measured using a hydrophone, for which the time transients of the sound pressure are shown in Fig. 6, in addition to the boiling behaviors. In the process of transitioning to MEB, the low sound pressure during the nucleate boiling changed to a strong sound pressure, similar to MEB in the open space. This confirms that spatial restriction can cause the transition to $\mathrm{MEB}$ prior to $\mathrm{CHF}$.

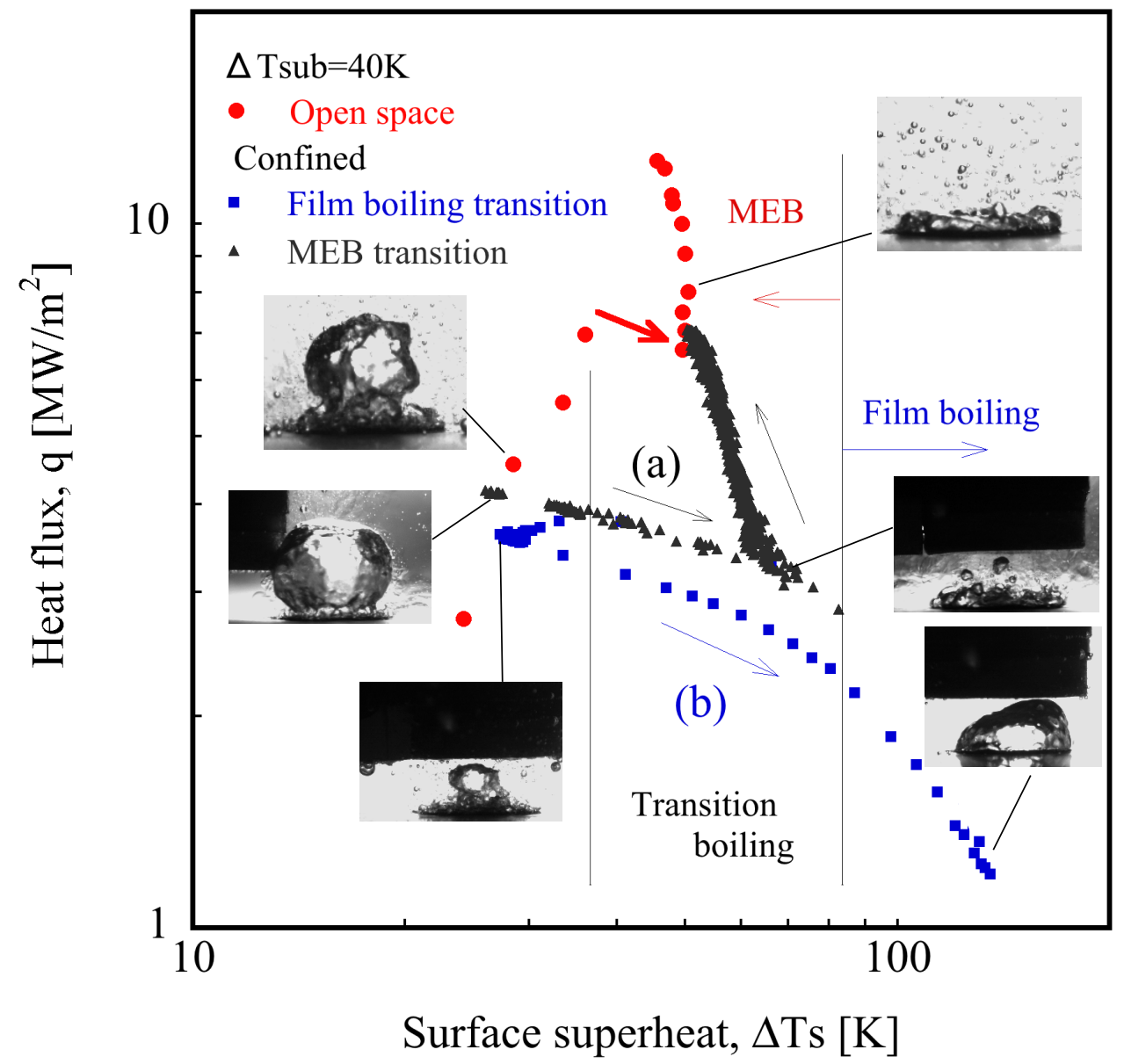

Fig. 5 Comparison of boiling curves for transition to MEB or film boiling.

These two transition patterns are examined thoroughly in this section using the boiling curve (Fig. 5) and high-speed video images (Fig. 6). First, when transitioning to MEB (a), the surface superheat increases and the heat flux gradually decreases. The switch occurred when the superheat ranges between $70 \mathrm{~K}-80 \mathrm{~K}$, wherein the superheat decreased but the heat flux could be increased. Subsequently, the same MEB region as the open space was achieved. In contrast, when transitioning to film boiling (b), there was no inversion of superheating and the heat flux, as well as the boiling pattern transitioned to film boiling. When the difference in the boiling curve from the video was examined, in the case of (a), the coalesced bubbles that were at the top $3 \mathrm{~mm}$ of the heat transfer surface (Fig. 7) gradually decreased in height due to spatial restriction, became thinner to the point of solid-liquid contact, and ultimately transitioned to MEB. The decreased height in coalesced bubbles was important, indicating that condensation at the top of the coalesced bubbles is superior to 


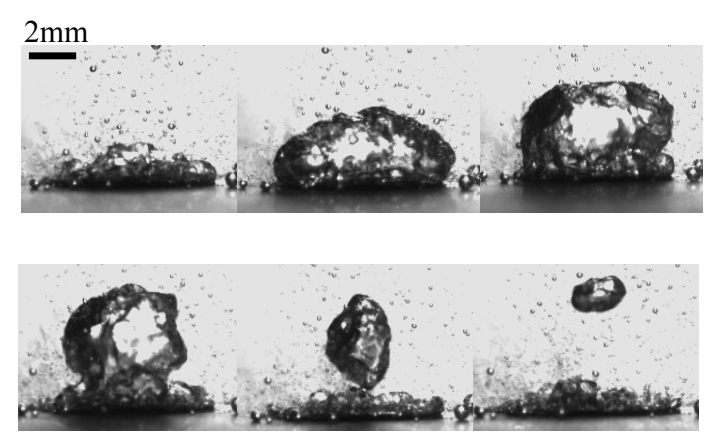

Nucleate boiling $\left(\mathrm{q}=4.7 \mathrm{MW} / \mathrm{m}^{2}, \Delta \mathrm{Ts}=30.5 \mathrm{~K}\right)$

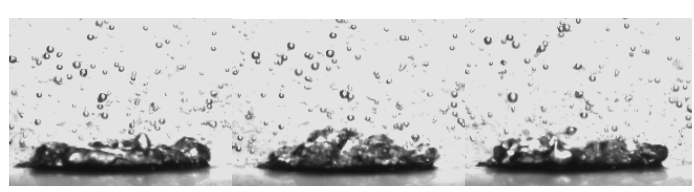

$\operatorname{MEB}\left(\mathrm{q}=8.3 \mathrm{MW} / \mathrm{m}^{2}, \Delta \mathrm{Ts}=53.7 \mathrm{~K}\right)$

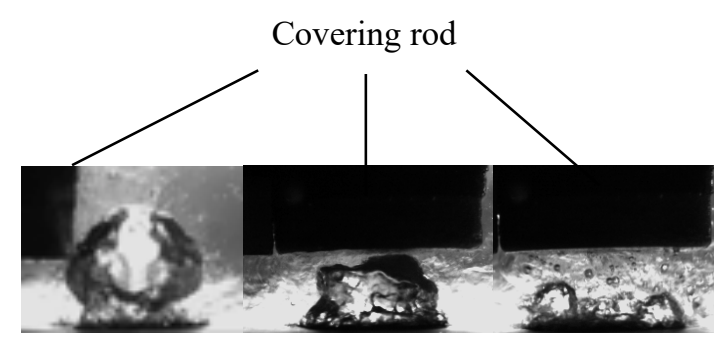

Transition process (a) to MEB
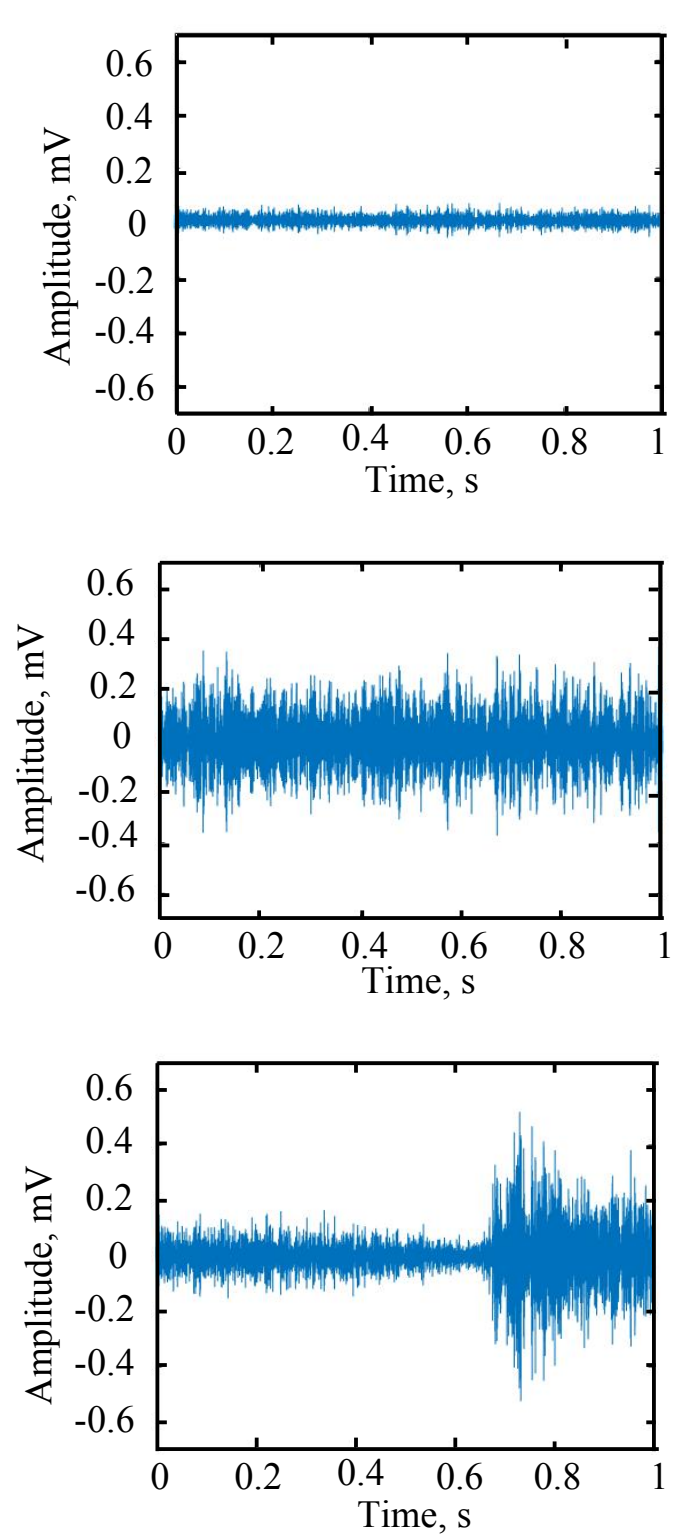

Fig. 6 Boiling behavior and sound signals at nucleate boiling, MEB, and transition process (a) to MEB in Fig. 5.

evaporation on the heated surface. As subcooled water entered the restricted space, the effect of condensation became stronger, increasing the possibility of solid-liquid direct contact. On the other hand, when transitioning to film boiling (b), as shown in Fig. 7, coalesced bubbles that were initially lower than the limited space gradually increased their height, filling the restricted space. This inhibited the subcooled water supply to the limited space, thereby transitioning to film boiling. If the difference in these two transition processes from a phenomenologically perspective is considered in Fig. 8 , in the case of (a), the space was filled with coalesced bubbles that restricted thermal transport due to condensation. Given that the heat flux and superheating in a restricted space is higher than (b), the dryout area on the heat transfer surface expanded, reducing the production of vapor and inhibiting the supply of vapor to the coalesced bubbles. As a result, the coalesced bubbles shrunk and collapsed. This shrinkage and collapse resulted in the emission of microbubbles, and subcooled water in contrast, moved to the heat transfer surface at a high speed, as explained by Kandlikar (2011). In the case of (b), there would be sufficient subcooled water in the space, despite a restriction. Thus, a liquid film supply to the heat transfer surface was possible, and expansion of the dryout area was not notable. Vapor supply to the coalesced bubbles due to evaporation continued, gradually growing coalesced bubbles and ultimately filling the restricted space. At this point, infiltration of the subcooled water was inhibited, and the effect of condensation could not be expected. The possibility of solid-liquid contact was eliminated, which was in a sufficient superheat region, thus, transitioning to film 
boiling. Expansion of the dryout area is important for both, transitioning to MEB (a) and for film boiling (b). However, based on the coalesced bubble behavior determined by evaporation and condensation, solid-liquid direct contact on the dried surface determines the transition style.

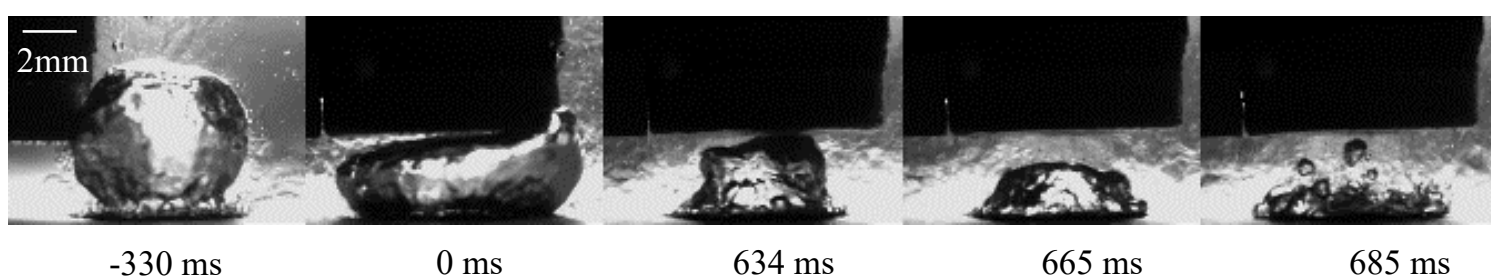

(a) Transition to MEB

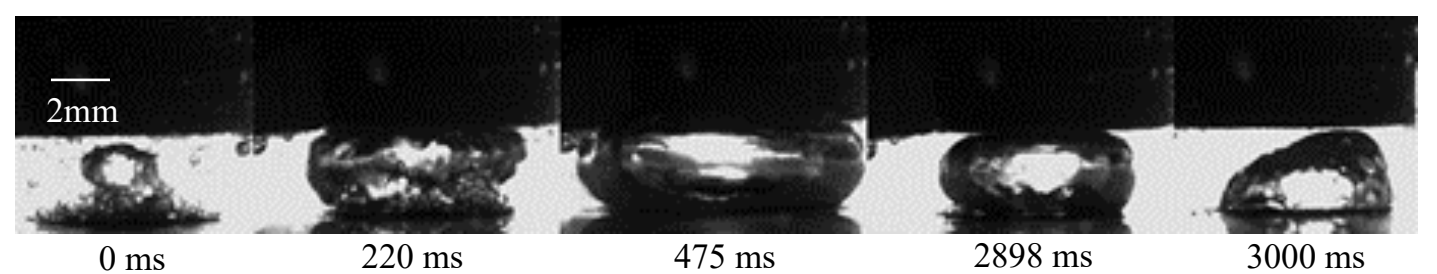

(b) Transition to film boiling

Fig. 7 Boiling behaviors in two transition cases.
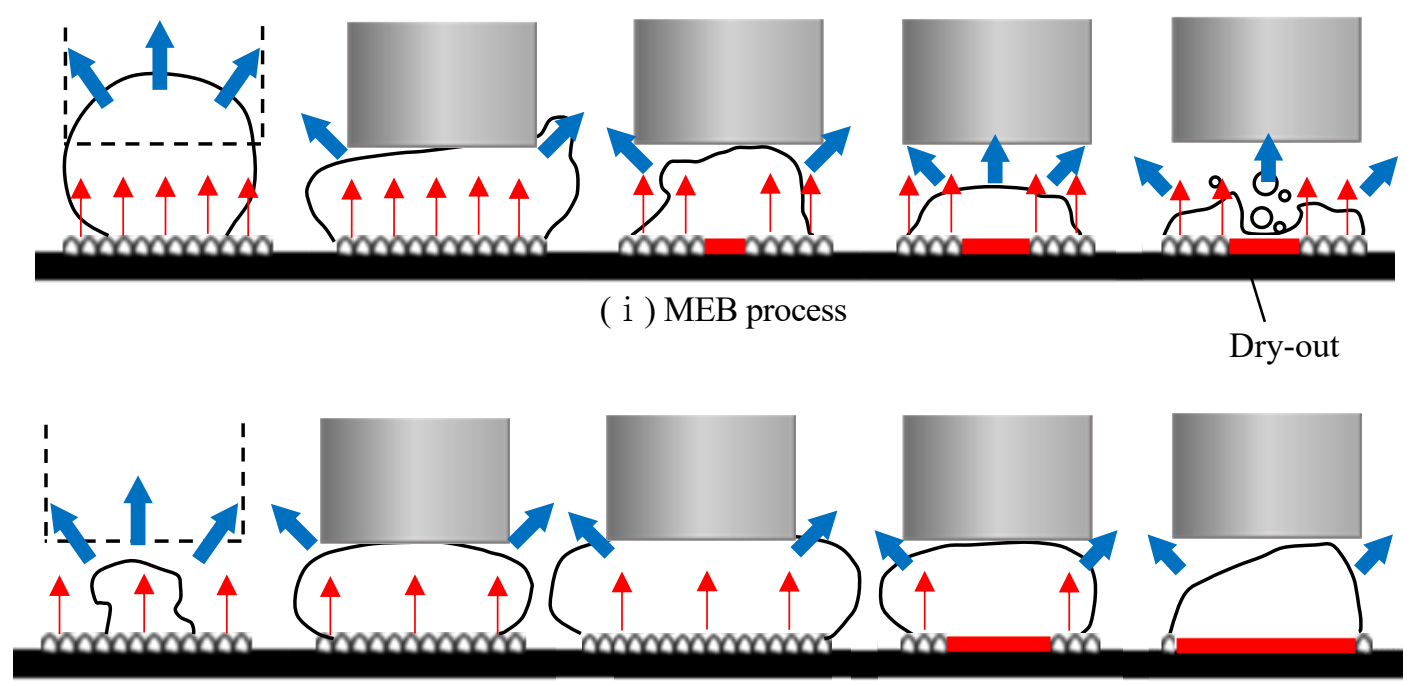

(ii ) Film boiling process

Fig. 8 Images of two-types of transition processes focusing on balances between evaporation and condensation.

\subsection{Possibility of solid-liquid direct contact based on Leidenfrost effect}

In Section 3.2, solid-liquid direct contact on the dryout area as the trigger for MEB transition was indicated. Utilizing the heat transfer surface used in the current boiling experiment, a $0.02 \mathrm{~mL}$ droplet sufficiently large to cover the heat transfer surface was placed under ambient air conditions, and the boiling behavior of the droplet was observed. Figure 9 presents the results. Similar to a typical Leidenfrost effect experiment, the behavior of the droplet could be classified into nucleate boiling, transition boiling, and film boiling.

As shown in Fig. 9, the nucleate boiling state achieved for the heat transfer surface was at approximately $120^{\circ} \mathrm{C}$ or lower in the low subcooled temperature region, and at $140^{\circ} \mathrm{C}$ or lower in the high subcooled temperature region. At approximately $180{ }^{\circ} \mathrm{C}$ or higher, the film boiling state was achieved. The surface temperature region between $120{ }^{\circ} \mathrm{C}$ or 


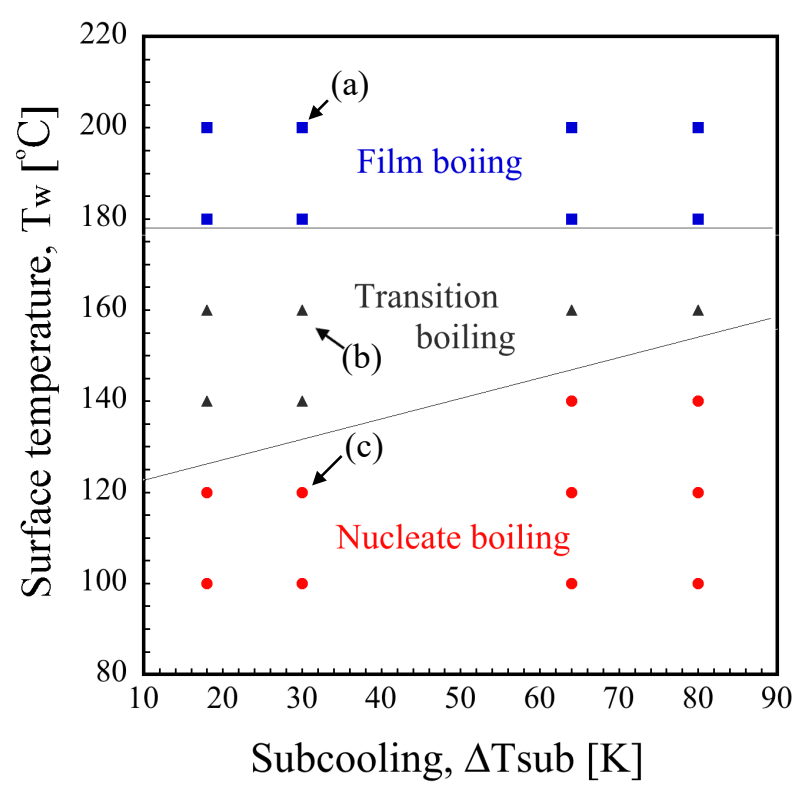

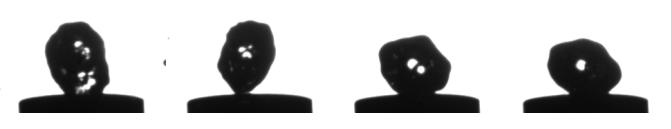

(a) Film boiling region

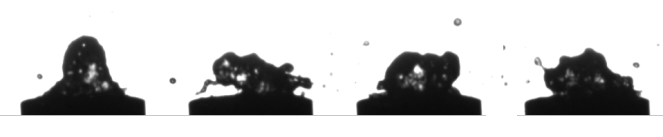

(b) Transition boiling region

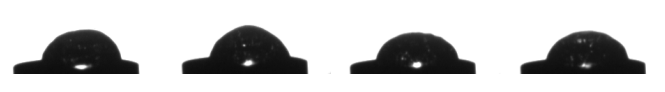

(c) Nucleate boiling region

Fig. 9 Boiling region map on relation to surface temperature and droplet behavior on heating surface.

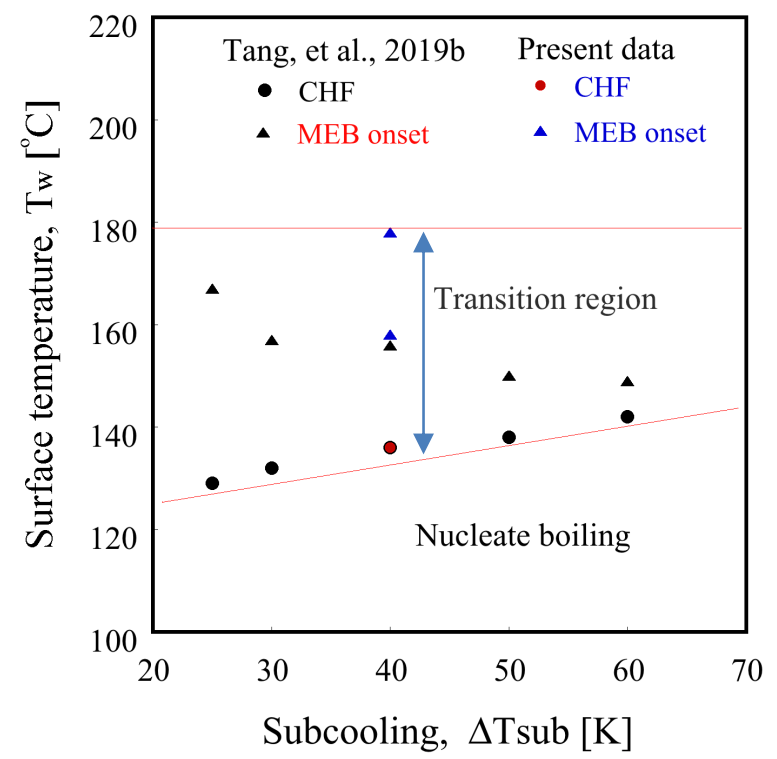

Fig. 10 Surface temperature at $\mathrm{CHF}$ and MEB onset points on boiling region map.

$140{ }^{\circ} \mathrm{C}$, and $180^{\circ} \mathrm{C}$ was in the transition boiling region. The boiling behavior acquired using the high-speed video showed that the bubbles formed in the droplet when the heat transfer surface temperature was approximately $120^{\circ} \mathrm{C}$ (point (c) in Fig. 9) or lower, confirming it to be in the nucleate boiling region. In addition, considering the heat transfer surface at $200{ }^{\circ} \mathrm{C}$ (Fig. 9 (a)), the vapor film formed between the droplet and heat transfer surface. This confirms the behavior wherein the droplet rolled down the heat transfer surface, i.e., the film boiling state. In contrast, at the heat transfer surface temperature of $160{ }^{\circ} \mathrm{C}$ (Fig. 9 (b)), which is in the intermediate temperature region, the droplet came into contact with the heat transfer surface, wherein small droplets were scattered. This scattering phenomenon is similar to vigorous boiling behavior in MEB, and a temperature region that transitions to MEB or film boiling is consistent with the transition boiling region. Therefore, it is assumed that as the dryout area increased in the transition boiling state, subcooled water came in direct contact with the heat transfer surface, transitioning to MEB, where there was vigorous interaction. This temperature range is lower than the temperature where vapor explosion occurs, which is not the temperature of spontaneous nucleation; thus, non-steady heat conduction due to direct contact supports heat transfer.

Figure 10 presents the surface temperature at CHF and onset of MEB as a function of subcooling, similar to Tang et al. (2019b). In this study, both CHF and MEB onset data points in an open space at a subcooling of $40 \mathrm{~K}$ in Fig. 3 are approximately the same as reported by Tang et al. Furthermore, the region where the MEB transition occurred in the 
confined space sufficiently corresponds to the transition boiling region for the droplet in Fig. 9. Therefore, the proposal by Tang et al. can be supported with a higher probability regarding the liquid to contact with the heating surface.

\subsection{Presumption of heat transfer mechanism}

Based on the previous sections, partial dryout has a significant effect on the transition to MEB; therefore, it is considered that the solid-liquid direct contact plays a significant role in the heat transfer process. The production of vapor was reduced in the MEB region, thus reducing the latent heat transport due to the evaporation of the liquid film on the heat transfer surface. Although a temporary reduction in heat flux over the CHF point was confirmed for MEB, there was an increase in the subsequent heat flux, and superheating decreased. This occurred due to the solid-liquid direct contact of the subcooled water on the dried surface, which potentially increased the sensible heat transport via non-steady heat conduction. Thus, considering the heat transfer mechanism of MEB, latent heat transport due to liquid film evaporation on the heat transfer surface and non-steady heat conduction at the time of solid-liquid direct contact on the dry surface, i.e., sensible heat transport, are closely involved in the high heat transfer properties of MEB. As indicated by the microlayer evaporation model in the high heat flux region near CHF (Zhao, et al., 2002), CHF is likely the maximum heat flux as a result of the contribution to the heat flux increase via the promotion of evaporation of the microlayer and the negative contribution to heat flux reduction by expansion of the dryout area caused by evaporation of the microlayer. Thus, in the high heat flux region of nucleate boiling, sensible heat transport due to solid-liquid direct contact on the dryout area is added to the latent heat transport due to evaporation of the microlayer. This leads to a positive contribution to heat transfer without any reduction in the heat flux, where MEB presents heat flux exceeding CHF. A detailed quantitative evaluation based on the heat transfer model is desired.

\section{Conclusion}

The growth of coalesced bubbles and shrinkage due to condensation were artificially regulated by restricting the subcooled water space over the heat transfer surface. Bubble behavior was observed with a high-speed video camera, boiling sounds were measured, and the respective boiling curve was acquired. The main conclusions are as follows:

1. In the high heat flux region of nucleate boiling prior to CHF, the space above the heat transfer surface was restricted. By causing an imbalance in the evaporation growth and condensation shrinkage of the coalesced bubbles, two transition patterns were obtained: from nucleate boiling to MEB, and from nucleate boiling to film boiling. When the subcooled temperature was $40{ }^{\circ} \mathrm{C}$ and the space above the heat transfer surface was limited to $3 \mathrm{~mm}$, it transitioned to MEB if the heat flux was $4 \mathrm{MW} / \mathrm{m}^{2}$ or higher, and to film boiling if the heat flux was below this value.

2. The bubbles that remain in the subcooled water are non-condensable gas, and their recovery increases in the nucleate boiling region in the same manner as the boiling curve. However, this recovery decreases in the MEB region. The height of the coalesced bubbles increases in the nucleate boiling region, but shrinks in the MEB region, becoming sufficiently thin to approach the heat transfer surface. Unlike the heat transfer mechanism that is dominated by evaporation latent heat in the nucleate boiling region, in the MEB region, sensible heat transport by solid-liquid direct contact is more effective.

3. Regarding the reproduction experiment of the Leidenfrost effect, the temperature region where MEB transition occurs was confirmed to be equivalent to the transition boiling region between nucleate boiling and film boiling, wherein the development of the dryout area and solid-liquid direct contact behavior are involved.

4. As a heat transfer model of MEB, the direct contact heat transfer in addition to the latent heat transfer due to the evaporation of the liquid layer on the heat transfer surface was proposed.

\section{Acknowledgements}

This work was supported by the Japan Society for Promotion of Science, Grants-in Aid for Scientific Research KAKENHI [grant number JP26630070]. 


\section{References}

Ando, J., Horiuchi, K., Saiki, T., Kaneko, T., Ueno, I., Transition process leading to microbubble emission boiling on horizontal circular heated surface in subcooled pool, International Journal of Heat and Mass Transfer, Vol.101 (2016), pp.240-250.

Inada, S., Miyasaka, Y., Izumi, R. and Owase, Y., Study on subcooled pool boiling characteristics curve (1st report, local heat transfer characteristics and effect of subcooling), Transactions of the Japan Society of Mechanical Engineers, Series B, Vol.47, No.417 (1981), pp.852-861 (in Japanese).

Ito, D., Natazuka, J., Saito, Y., Velocity field measurement in micro-bubble emission boiling, Transactions of the JSME (in Japanese), Vol.83, No.847 (2017), DOI:10.1299/transjsme.16-00428.

Kandlikar, S. G., Thermofluid dynamics of boiling in microchannels, Part 2, Advances in Heat Transfer, Vol.43 (2011), pp.159-226.

Kishihara, K., Tsuruta, T., Tanigawa, H., Study on microbubble emission boiling based on microlayer model, Proceedings of the First Pacific Thermal Engineering Conference (2016), PRTEC-15074.

Kumagai, S., Kubo, R., Bubble motion in micro-bubble emission boiling, Transactions of the Japan Society of Mechanical Engineers, Series B, Vol.65, No. 629 (1999), pp.296-300 (in Japanese).

Kumagai, S., Uhara, T., Nakata, T., Izumi, M., Liquid-solid contact in microbubble emission boiling through void signals, Transactions of the Japan Society of Mechanical Engineers, Series B, Vol.67, No.661 (2001), pp.154-160 (in Japanese).

Nakamura, J., Tsuruta, T., Tanigawa, H., A study on mechanism of microbubble emission boiling, Transactions of the JSME (in Japanese), Vol.84, No. 859 (2018), Doi:10.1299/transjsme.17-00405.

Ono, A., Sakashita, H., Measurement of surface dryout near heating surface at high heat fluxes in subcooled pool boiling, International Journal of Heat and Mass Transfer, Vol.52 (2009), pp.814-821.

Suzuki, K. and Inagaki, R., A fundamental study on high heat flux cooling using sub-cooled flow boiling with microbubble emission, Proceedings of the 5th International Conference on Enhanced, Compact and Ultra-compact Heat Exchangers: Science, Engineering and Technology (2005), CHE2005-37.

Suzuki, K., Topics of boiling heat transfer: Microbubble emission boiling observed in highly subcooled boiling, Boiling (2017), pp.530-548, Elsevier.

Tang, J., Mo, Z., Sun, L., Yan, C., An experimental study on microbubble emission boiling in a subcooled pool: Heat transfer characteristics and visualized presentation, Experimental Thermal and Fluid Science, Vol.80 (2017), pp.4052.

Tange, M., MEMS technology for fundamental research of microbubble emission boiling, Boiling (2017), pp.548-561, Elsevier.

Tang, J., Xie, G., Bao, J., Mo, Z., Liu H., Du. M., Experimental study of sound emission in subcooled pool boiling on a small heating surface, Chemical Engineering Science, Vol.188 (2018), pp.179-191.

Tang, J., Sun, L., Wu, D., Du. M., Xie, G., Yang K., Effects of ultrasonic waves on subcooled pool boiling on a small plain heating surface, Chemical Engineering Science, Vol.201 (2019a), pp.274-287.

Tang, J., Sun, L., Du, M., Liu, H., Mo, Z., Bao, J., Experimental investigation of transition process from nucleate boiling to microbubble emission boiling under transient heating modes, AIChE Journal (2019b), Doi:10.1002/aic. 16555.

Ueno, I., Ando, J., Koiwa, Y., Saiki, T., Kaneko, T., Interfacial instability of a condensing vapor bubble in a subcooled liquid, The European Physical Journal Special Topics, Vol.224 (2015), pp.415-424.

Ueno, I., Osawa, T., Hattori, Y., Saiki, T., Ando, J., Horiuchi, K. and Koiwa, Y., Vapor bubble behaviors in condensation, Boiling (2017), pp.548-561, Elsevier.

Unno, N., Yuki, K., Kibushi, R., Satake, S., Suzuki, K., Subcooled pool boiling with an eroded heating surface by microbubble emission boiling, Proceedings of the 28th International Symposium on Transport Phenomena (2017) Peradeniya, Sri Lanka.

Zeigarnik, Yu. A., Platonov, D. N., Khodakov, K. A. and Shekhter, Yu. L., The nature of microbubble emission under subcooled water boiling, High Temperature, Vol.50, No.1 (2012), pp.78-83.

Zhao, Y.H., Masuoka, T. and Tsuruta, T., Unified theoretical prediction of fully developed nucleate boiling and critical heat flux based on a dynamic microlayer model, International Journal of Heat and Mass Transfer, Vol.45, No.15 (2002), pp.3189-3197. 